\title{
Integrating the hedonic and eudaimonic perspectives to more comprehensively understand wellbeing and pathways to wellbeing
}

\author{
Luke Wayne Henderson • Tess Knight
}

\begin{abstract}
Recently, the disagreement that separates hedonic from eudaimonic philosophers has spread to the science of wellbeing. This has resulted in two opposing perspectives regarding both wellbeing concepts and proposed pathways to wellbeing. Whilst contention continues, most contemporary psychologists now agree that hedonic and eudaimonic approaches each denote important aspects of wellbeing. This has led to integrated wellbeing conceptualisations, in which the combined presence of hedonic and eudaimonic wellbeing components is referred to as 'flourishing'. In regard to the attainment of wellbeing, research simultaneously investigating hedonic and eudaimonic pathways suggests that a life rich in both types of pursuits is associated with the highest degree of wellbeing. Despite this assertion, previously underemphasised methodological limitations question the validity of such claims. To further progress this important area of investigation, future research directions to ameliorate said limitations are explored. It is recommended that the past tendency to contrast and compare hedonia and eudaimonia be abandoned, and instead that the inherent value of both be recognised. Time-use research methods are needed to cross-validate past findings obtained from cross-sectional research, which will make it possible to transition from purely descriptive conclusions to applied conclusions.
\end{abstract}

Keywords: pleasure, meaning, hedonia, eudaimonia, wellbeing, well-being, happiness, flourishing, pathways, positive psychology, integration

\section{Introduction}

How to achieve optimal psychological wellness has always been a fundamental enquiry regarding human life. Despite this, psychological research over the past half century has focused almost exclusively on psychopathology (Seligman \& Csikszentmihalyi, 2000). In more recent years, the emergence of positive psychology has lifted the taboo surrounding research into areas such as happiness and wellbeing, resulting in an abundance of research interest (Linley, Joseph, Harrington, \& Wood, 2006). Despite much interest, multiple and sometimes opposing perspectives have since been postulated regarding not only the constituents of wellbeing, but also ways in which one can optimise one's personal experience of wellbeing.

Past dissent pertaining to the nature and pursuit of happiness and wellbeing resulted in the establishment of two opposing philosophical traditions: hedonia and eudaimonia (Grinde, 2012). The hedonic perspective suggested that maximising one's pleasurable moments was the pathway to happiness, whilst eudaimonic advocates argued that living a life of virtue, and actualising one's inherent potentials was the way to wellbeing (Delle Fave, Massimini, \& Bassi, 
2011b). These philosophical traditions have since been translated to contemporary psychology for the development of a science of wellbeing. This translation of philosophical ideas to psychological constructs has not been without contention, and the usefulness or even existence of such a distinction has recently been debated at length (Kashdan, Biswas-Diener, \& King, 2008; Waterman, 2008). Despite contention, eminent psychologists now appear to see the benefits of both hedonic and eudaimonic approaches, which has resulted in the emergence of integrated wellbeing conceptualisations (e.g. Huppert \& So, 2009), which use the term 'flourishing' to describe the combined presence of both hedonic and eudaimonic wellbeing concepts. Such methodologies comprehensively capture both the nature of wellbeing, and the potential pathways to the attainment of wellbeing. Whilst research utilising integrated methodologies remains in its infancy, emerging from the literature is the suggestion that a life rich in both hedonic and eudaimonic pursuits is associated with the greatest degree of wellbeing (Huta \& Ryan, 2010).

This article reviews the philosophical origins of the two traditions and delineates the various perspectives held by contemporary psychologists. Possible conclusions and recommendations are made, namely for the continued pursuit of both hedonic and eudaimonic approaches with an emphasis on integration rather than comparison. Research investigating eudaimonia and hedonia in parallel terms is then critically reviewed as such studies reflect a vital attempt to abandon dichotomous thinking, which makes it possible to observe the interrelationship between hedonia and eudaimonia. The implications and limitations of the reviewed studies are discussed, and future research directions aimed at ameliorating past methodological limitations are proposed to further progress this important research focus.

\section{Background}

\subsection{Two philosophical traditions}

Underlying this contemporary psychological debate are two ancient Greek philosophical traditions: hedonia and eudaimonia (Delle Fave et al., 2011b). A detailed review of these philosophical underpinnings is beyond the scope of this paper; however, a brief review is necessary to lay the foundations for this contemporary discussion. The hedonic tradition can be traced back to philosophers such as Aristippus, Epicurus, Bentham, Locke, and Hobbes (Waterman, 2008). Philosophers adopting the hedonic perspective generally equated wellbeing with the positive emotional states that accompany satisfaction of desire; therefore experiences of pleasure, carefreeness, and enjoyment were considered reflective of wellbeing (Diener, 2009). Hedonic philosophers believed that humans essentially desire to maximise their experience of pleasure and to minimise pain; pleasure and pain were seen as powerful indicators of good and bad and hence maximising pleasure was seen as a way of maximising the good in one's life. Hedonic philosophers traditionally took a 'subjectivist' position, in that the individual is considered to be in the best position to determine how well they are.

The eudaimonic tradition is often contrasted with, and considered philosophically opposed to, the hedonic tradition (Deci \& Ryan, 2008). The concept of eudaimonia was first explicated by Aristotle (Aristotle, 1985); however, it has also been linked to other ancient philosophers such as Plato and Zeno of Citium (Grinde, 2012). Aristotle proclaimed that living a life of contemplation and virtue, in accordance with one's inherent nature (i.e. living authentically, or in truth to one's 'daimon') was the pathway to wellbeing (Norton, 1976). Aristotle defined acting virtuously as behaving in a way that is noble and is worthwhile for its own sake; often emphasising the virtues of justice, kindness, courage, and honesty. Aristotle further suggested that developing one's potentials in the pursuit of complex and meaningful (both to the 
individual and society) goals was the hallmark of a good life (Keyes \& Annas, 2009). He distinguished between pleasure and the good life, at times denigrating hedonism as a vulgar ideal, as he believed it made humans the slaves of desires. Positive emotional experiences were not central to Aristotle's conception of a good life, though he did acknowledge that often the result of eudaimonic action was hedonic pleasure (Kashdan et al., 2008). Aristotle did not denigrate hedonic pleasure per se, but rather, the pursuit of hedonic pleasure purely for pleasure's sake (Waterman, 2008). Aristotle's conception of eudaimonia has predominantly been considered an objective approach, where a life is judged from the outside, according to whether it was a life of excellence and virtue (McDowell, 1980). This approach represents a concern that hedonic happiness and satisfaction can result from reprehensible behaviour, and therefore subjective reports of happiness should not be considered a good indication of whether a life is well lived. As subjective pleasure can be experienced in many contexts (e.g. through the use of illicit drugs), positive subjective reports may not always be reflective of wellness. ${ }^{1}$ This would suggest that eudaimonic philosophers are more concerned with why someone is happy, rather than if someone is happy.

\subsection{From philosophy to science}

Philosophers and psychologists often inspire each other's work, which has led to the attempted adaptation of the aforementioned philosophical approaches to the psychology of wellbeing (Kahneman, Diener, \& Schwarz, 1999; Waterman, 1993). Hedonic psychological approaches have generally considered wellbeing an internal state which represents a variety of subjective evaluations about the quality of one's life, broadly defined (Delle Fave et al., 2011b). This conception generally translates to the construct of subjective wellbeing (SWB), which has typically been considered to include an affective component, consisting of a preponderance of positive emotional experiences over negative emotional experiences, and a cognitive component, which refers to a personal judgment on the satisfaction one has with life as a whole, or with specific life domains, such as work or relationships (Diener, 2009). At the activity or pathway level (i.e. wellbeing-promoting behaviours), hedonic approaches have typically emphasised the importance of engaging in pursuits that afford positive emotional experiences (such as pleasure, comfort, entertainment, and enjoyment) and that lead to the satisfaction of one's desires (Fredrickson, 2001; Kahneman, 1999). An accumulative effect is assumed, whereby high degrees of wellbeing are experienced by satisfying one's personal desires and increasing the frequency of one's pleasurable moments (Fredrickson, 2004).

Whilst there has been general consensus amongst hedonic psychologists about wellbeing indicators and pathways, there has been more ambiguity surrounding the translation of eudaimonia to psychology (Kashdan et al., 2008). This has led to the emergence of a variety of theories and approaches, with personal growth and meaning in life often emphasised as core eudaimonic components (Delle Fave et al., 2011b). Other constructs that have also been linked to the eudaimonic perspective include purpose, autonomy, competence, self-realization, mindfulness, self-acceptance, authenticity, values congruence, and social connectedness (Baumeister \& Vohs, 2002; Huta \& Ryan, 2010; Ryan \& Deci, 2000). What becomes immediately apparent is that eudaimonia seems a more complex and elusive concept than hedonia. Eudaimonic approaches also emphasise that wellbeing and happiness are on-going processes, not end states. Despite this, like hedonia, eudaimonia has been considered at both the wellbeing and activity levels, with activities that are intrinsically motivated and afford

\footnotetext{
${ }^{1}$ For a detailed review of the difficulties with both subjective and objective measures see Tiberius and Hall (2010).
} 
development in oneself often emphasised as pathways to wellbeing (Huta, 2012). Hedonia and eudaimonia have, therefore, both been considered as ways of living/behaving, and more globally, as wellbeing types.

\subsection{Recent debate}

As previously alluded to, this translation of philosophical ideas to psychological constructs has not been without contention (Ryan \& Deci, 2001). The costs and benefits of adopting these philosophical ideas within the science of wellbeing have recently been debated at length by many of the leading researchers in the field. Although the goal of this article is not to add further commentary to this debate, it is necessary for the authors to summarise the main points in order to delineate their position. Kashdan et al., (2008) began the conversation by suggesting that the philosophical distinction between hedonia and eudaimonia was unhelpful, unwarranted empirically, and potentially harmful. They levelled their argument primarily at the lack of scientific rigour which they believed has characterised eudaimonic approaches. They argued that the heterogeneity of proposed eudaimonic definitions and theories added an unnecessary layer of complexity, which interfered with scientific advancement. Kashdan et al. stated that Aristotle's conception of eudaimonia was inappropriate for psychological science as it had inherent moral judgments, and was elitist, as it implied that eudaimonia was a state reserved for/achievable by only a select few (i.e. those with unique potentials). They further suggested that there was an implicit (and sometimes explicit) erroneous assumption that eudaimonic wellbeing was more objective, comprehensive, and morally valid than SWB. Kashdan et al. also expressed particular concern with the suggestion that eudaimonia was distinct from hedonia, and suggested that findings from research (see Waterman, 1993) proposed as evidence that hedonia and eudaimonia were quantitatively distinct, could easily be interpreted as evidence that they are part of the same construct. They argued that as hedonic and eudaimonic measures were often found to share a high degree of variance, results should be interpreted as evidence that there are quantitative distinctions among a matrix of wellbeing dimensions, as opposed to two qualitatively different kinds of happiness and wellbeing. Kashdan et al. argued for the abandonment of a hedonic and eudaimonic categorical dichotomy, and recommended instead that explicit reference be made to whatever construct is under investigation (e.g. meaning in life), rather than a general reference to the philosophical tradition that the construct might be aligned with (e.g. eudaimonia).

Waterman (2008) was first to respond, arguing that it was premature to consider abandoning eudaimonic approaches on the grounds of a lack of conceptual clarity. Waterman highlighted that it was unsurprising that hedonic approaches enjoyed more scientific consensus, as they had been investigated for decades longer, and have a disproportionately larger body of research compared to eudaimonic approaches. Waterman (2008) argued that having a variety of definitions was appropriate during early stages, and that those operational definitions that emerge which correspond adequately to conceptual meanings would be the ones that survive. Waterman further suggested that a purely empirically-driven approach ignored the complexities of the wellbeing construct. Ryan and Huta (2009) agreed, suggesting that scientific rigour did not mean an absence of theory. They interpreted the current diversity within the wellbeing research focus as positive, and described the recent tension between hedonic and eudaimonic advocates as a generative, creative tension.

In response to Kashdan et al.'s (2008) concern with Aristotle's conception of eudaimonia, Waterman (2008) argued that contemporary psychological approaches needed to consider contemporary eudaimonic philosophy, and that whilst Aristotle may have adopted an objective 
approach, current eudaimonic philosophers proposed that eudaimonia can be investigated as a subjective experience (see Tiberius \& Hall, 2010). Waterman's conceptualisation of eudaimonia emphasises the importance of developing one's potentials, and living in accordance with one's daimon (i.e. one's true self), and therefore, Waterman has generally investigated eudaimonia at the activity level. Other conceptualisations have emphasised the quality of one's life as a whole (i.e. eudaimonic wellbeing); where hedonic wellbeing has emphasised the importance of feeling good, eudaimonic wellbeing has often been defined in terms of functioning well (Keyes \& Annas, 2009; Ryan \& Huta, 2009). Ryan and Huta expressed concern that if SWB were to be the only indicator of wellness, then more happiness would equate to more wellness, which ignores both the source of happiness and the functioning of the individual. Ryan and Huta admitted that SWB can be a good indicator of wellness, but only when considered in the context of the functions, values, and behaviours that engender it, which is to say, when it is considered in conjunction with eudaimonia. Keyes and Annas (2009) agreed that functioning was an important consideration, and whilst they admitted that feelings and functioning in life would often be consistent (i.e. overlapping), they cited evidence suggesting that they are not redundant, conceptually or empirically ${ }^{2}$ (Keyes, 2006; Keyes et al., 2008). Delle Fave and Bassi (2009) added another element to this argument, suggesting that at times an individual may be healthy and functioning well, despite not feeling good in their life. One example they provided was when an individual is grieving the loss of someone, whereby a decrease in SWB would be considered part of an entirely healthy process. Furthermore, periods of uncertainty and adjustment are often associated with meaning-making and personal growth yet can also be associated with decreased SWB (Vittersø \& Søholt, 2011). These examples question whether SWB alone is an adequate indicator of wellbeing, and suggest that eudaimonic approaches represent an important adjunct to SWB.

Kashdan et al.'s (2008) suggestion that hedonia and eudaimonia are not distinct was also opposed by Waterman (2008). Waterman drew from his own research (Waterman, 1993; Waterman, Schwartz, \& Conti, 2008), which found that whilst eudaimonic activities were highly associated with hedonic enjoyment, hedonic enjoyment was often found to arise in the absence of eudaimonia, and therefore they are distinct ${ }^{3}$. Whilst Waterman focused on the distinction between hedonia and eudaimonia at the activity level, Keyes and Annas (2009) argued that hedonia and eudaimonia are distinct at the wellbeing level. They referred to Keyes's Complete Mental Health Model as evidence; specifically, the comparison between individuals who have both high degrees of SWB and of eudaimonic wellbeing (i.e. those considered to be "flourishing", which constituted $18 \%$ of the sample) and those that have only high degrees of SWB (i.e. those considered to be moderately mentally healthy, which constituted $48.5 \%$ of the sample). These two groups were found to differ in meaningful ways; flourishing individuals experienced less impairment and were less of a burden on society than moderately mentally healthy individuals as measured by greater work productivity, decreased disability, decreased risk of cardiovascular disease, decreased rates of physical illness, decreased healthcare utilisation and superior psychosocial functioning. These meaningful differences supply direct support for the utility of the eudaimonic and hedonic distinction. Keyes and Annas concluded that not enough people are functioning well in a life about which they feel good, which provides a strong rationale for both the distinction between hedonia and

\footnotetext{
2 This research is discussed in more detail later in the article

${ }^{3}$ This study is reviewed at length later in this article
} 
eudaimonia, and for the development of empirically validated interventions aimed at increasing eudaimonia to promote flourishing.

In response to Kashdan et al.'s (2008) concern about the potential elitism inherent in eudaimonic approaches, Waterman (2008) suggested that this argument again reflected a misunderstanding of contemporary eudaimonic philosophers. Contemporary approaches deemphasise strivings for some particular excellent outcome, and instead emphasise the need to consider the individual, and the individual's unique potentials. Therefore, if a person is developing within themselves, and in accordance with their own unique potentials, they are considered to be experiencing eudaimonia. As such, everyone has the capacity to experience eudaimonia, not just a select few. Waterman proposed that Kashdan et al.'s concerns about eudaimonia being considered more morally valid than SWB was a moot point from a scientific perspective, as what is "better" is a deontological claim, and therefore beyond the scope of scientific inquiry.

It is clear from this brief review that there remains contention around the translation of philosophical perspectives to the science of wellbeing, and that this healthy debate is likely to continue. Despite this, it is possible to postulate some conclusions. Firstly, contemporary psychological approaches have clear and explicit links to the philosophical conceptions of hedonia and eudaimonia, and therefore we see no problem with the continued use of this terminology. Secondly, it is apparent that there is a distinction between hedonia and eudaimonia, and a meaningful one at that. Although both hedonic and eudaimonic pursuits may be highly related (i.e. an activity may be experienced as hedonic and eudaimonic), an activity can be experienced as hedonic in the absence of eudaimonia, and therefore they are distinct. Furthermore, at the wellbeing level, a distinction between feelings about one's life and functioning seems vitally important to a comprehensive understanding of the mental health continuum. Thirdly, whilst eudaimonic advocates argue that SWB is not an adequate indicator of wellbeing by itself, they do still value SWB and hedonic approaches and consider them important dimensions of the overall wellbeing picture. This is an important point as it illustrates that despite past disagreement, contemporary psychologists recognise the strengths and value of both traditions. Lastly, eudaimonic approaches are still very much in their developmental stages; however, they contribute meaningfully and importantly to a comprehensive understanding of wellbeing. Despite this, eventually eudaimonic researchers will need to either come to a consensus, or better delineate the different perspectives into meaningful theories.

\subsection{Flourishing}

It is the common ground amongst the various aforementioned perspectives that appears most appealing and constructive. All agree that there is a need to continue to investigate a broad array of wellbeing and happiness sources and outcomes, from both the hedonic and eudaimonic traditions, and that this type of cross-fertilisation will increase our overall understanding of happiness and wellbeing. All agree that eudaimonia and hedonia should not be treated categorically, nor considered mutually exclusive, but rather that hedonia and eudaimonia operate in tandem, in a synergistic fashion. Therefore, there should be flexibility in studying interrelationships among the constructs. All agree that there is as much worth in studying the complementarity of hedonic and eudaimonic models as in studying difference. Finally, there is general consensus that a state characterised by both hedonic and eudaimonic sources and outcomes is most desirable. It is for these reasons that we now turn our attention towards integrated wellbeing conceptualisations. 
Various researchers have recently aimed to combine the two conceptualisations as a means of more comprehensively capturing wellbeing; the assumption being that both hedonia and eudaimonia denote important components of an overarching wellbeing construct. Seligman, Parks and Steen (2004) were first to propose an integrated wellbeing theory termed Authentic Happiness theory, which suggested that the presence of positive emotion, meaning, and engagement were indicative of wellbeing. The dimensions of pleasure and of meaning in Seligman et al.'s model have been equated with hedonia and eudaimonia respectively. The dimension of engagement has been equated with flow, which is a state characterised by intense absorption in one's activities, where a person's skill and the challenge of an activity are well matched, and both are high (Csikszentmihalyi, 1997). As flow is often induced by activities that afford personal growth, a theoretical link has been proposed between flow and eudaimonia (Waterman, 1993). Despite this, an individual can experience flow whilst engaged in less virtuous and meaningful activities (e.g. flow is commonly experienced whilst playing video games, see Hsu \& Lu, 2004), and therefore engagement should be considered distinct from, but related to, eudaimonia. More recently, Seligman added the facets of achievement and relationships to his definition, and labelled the combined presence of all components 'flourishing' (Seligman, 2011). Seligman proposes that his new theory reconciles the differing perspectives regarding the conceptualisation and measurement of wellbeing by including both hedonic and eudaimonic aspects (Forgeard, Jayawickreme, Kern, \& Seligman, 2011). Although there is currently a lack of empirical support, Seligman claims he is in the process of developing measures to investigate the validity of his flourishing theory of wellbeing (Forgeard et al., 2011). Keyes (2007) proposed a similar model of wellbeing, which suggests that flourishing includes "symptoms" of both hedonia and eudaimonia. Keyes's Complete Mental Health Model includes the facets of emotional wellbeing (i.e. SWB) and positive functioning in life (i.e. eudaimonic wellbeing), which includes psychological wellbeing and social wellbeing. 'Flourishing' is now often used (as it will be for the remainder of this article) to describe the desirable state whereby both hedonic and eudaimonic facets of wellbeing are simultaneously present within an individual (Huppert \& So, 2009).

\subsection{Pathways to wellbeing}

Much of the research investigating pathways to wellbeing has subscribed to either the hedonic or the eudaimonic perspective, utilising a unilateral approach and studying that pathway in isolation (Delle Fave, Brdar, Freire, Vella-Brodrick, \& Wissing, 2011). Findings from such research have supported the effectiveness of both hedonic (e.g. Fredrickson, 2004) and eudaimonic (e.g. Steger, Kashdan, \& Oishi, 2008) pathways; however, it is noteworthy that in such research wellbeing has typically been conceptualised consistently with the philosophical perspective of the researcher. That is, an advocate of a eudaimonic approach investigating eudaimonic pathways to eudaimonic wellbeing (e.g. Waterman et al., 2003), or an advocate of a hedonic approach investigating hedonic pathways to hedonic wellbeing (e.g. Fredrickson, 2000). This unilateral approach has been increasingly criticised (see Biswas-Diener, Kashdan, \& King, 2009), as conclusions cannot be made in regard to the relative effect of hedonic pathways on eudaimonic wellbeing or eudaimonic pathways on hedonic wellbeing. It is now acknowledged that hedonia and eudaimonia are not mutually exclusive (Waterman et al., 2008), and that eudaimonic pursuits can have positive influences on hedonic wellbeing, and vice versa (e.g. King, Hicks, Krull, \& Del Gaiso, 2006). This recognition has led to more recent attempts to simultaneously investigate eudaimonic and hedonic pathways, which is where we now turn our attention. 


\section{Integrated methodologies: A critical review}

This section will review and critically analyse research pertaining to hedonia and eudaimonia. Whilst not a systematic review per se, the authors considered only those studies that assessed eudaimonia and hedonia in parallel terms. This inclusion criterion was applied because such studies reflect an attempt to integrate the investigation of the hedonic and eudaimonic perspectives, which represents an emerging and important research direction. Studies utilising such methodologies have been either conceptual in focus, or have been more concerned with how hedonic and eudaimonic pursuits influence overall wellbeing (i.e. pathways to wellbeing). Conceptual research has attempted to add clarity to the constructs of hedonia and eudaimonia so as to better understand, define and operationalize them. Pathways research has attempted to answer questions pertaining to how personal wellbeing is achieved through the engagement in hedonic and eudaimonic activities. This section will delineate these two research foci.

\subsection{Conceptual focus}

The first instance of the simultaneous investigation of hedonia and eudaimonia can be traced to Waterman (1993). Waterman investigated hedonia and eudaimonia as subjective states experienced whilst engaged in certain activities. His aim was to ascertain whether hedonia and eudaimonia were distinct experiences. He developed the Personally Expressive Activities Questionnaire (PEAQ), which required participants to select five activities of importance which they would use to communicate who they are and what they are like as a person. Participants were then required to rate, on 7-point scales, how much they typically experienced eudaimonia (e.g. "this activity gives me my strongest feeling that this is who I really am", "when I engage in this activity I feel more intensely involved than I do in most other activities", etc.) and hedonia ("this activity gives me my strongest sense of enjoyment", "this activity gives me my greatest pleasure") whilst engaged in their selected activities.

Consistent with Waterman's (1993) hypotheses, experiences of eudaimonia and hedonia were found to be highly related (correlations ranged from 0.71 to 0.86); however this relationship was found to be asymmetrical: activities that were experienced as eudaimonic but not hedonic were reported significantly less than activities that were experienced as hedonic but not eudaimonic. Both eudaimonic and hedonic activities were accompanied by positive cognitive-affective states to a comparable degree. However, eudaimonic activities were found to be strongly associated with opportunities to develop one's best potentials, investing a great deal of effort, having clear goals, feeling assertive, feeling challenged, having a high level of concentration, and knowing how well one was doing, whereas hedonic activities were strongly associated with feeling relaxed, excited, content, happy, losing track of time, and forgetting one's personal problems. From these findings Waterman concluded that a distinction could reliably be drawn between the subjective states of eudaimonia and hedonia, the most important of which was that eudaimonia afforded opportunities for an individual to advance their personal potentials, whether in terms of skills and talents, purposes in living, or both.

Waterman and colleagues (Waterman et al., 2008) have since replicated this study, with slight methodological adjustments. Waterman et al. believed that prior conceptions of intrinsic motivation (i.e. activities that are enjoyed in-and-of-themselves) were inadequate, and argued that intrinsic motivation should be reserved for those activities that give rise to the development of one's potential (i.e. eudaimonic activities). They proposed that activities where just hedonic enjoyment was experienced should be considered hedonically motivated, whilst activities where both hedonia and eudaimonia were experienced represented true intrinsically 
motivated activities. Again the PEAQ was used; however, two subjective conditions previously proposed as defining characteristics of intrinsic motivation were added: interest (Deci \& Ryan, 1985) and the characteristics of flow (i.e. having clear goals, not feeling self-conscious, being in control, losing track of time, knowing you are doing well, intense concentration, forgetting personal problems, and being fully involved) as specified by Csikszentmihalyi (1991). A further four variables, previously suggested as distinguishing intrinsically motivated activities from others were also included: self-determination (Ryan, 1992), the balance of challenges and skills (Csikszentmihalyi, 1988), self-realisation values (Waterman, 1990), and the level of effort invested in the performance of the activity (Waterman, 2005).

Findings were consistent with Waterman's (1993) previous study, in that the subjective experiences of hedonia and eudaimonia were highly correlated $(>0.80)$, and an asymmetrical relationship was observed. When specifically comparing intrinsically motivated activities (i.e. those experienced as highly eudaimonic and hedonic) and hedonically motivated activities (i.e. those experienced as highly hedonic only), the former were found to be associated with higher scores on all four variables linked to self-realisation (i.e. balance of challenges and skills, selfrealisation values, level of effort, and importance) and were rated as higher on both interest and flow experiences. However, no difference was found for self-determination or frequency. Despite not distinguishing intrinsically motivated activities from hedonically motivated activities, self-determination was found to be the strongest independent predictor of both types of subjective experiences (i.e. hedonic and eudaimonic). Therefore, Waterman concluded that self-determination is a necessary, but not sufficient condition for intrinsic motivation, which runs counter to previous theories (see Ryan, 1992). Waterman argued that as both hedonically motivated and intrinsically motivated activities are enjoyed in-and-of-themselves, it is not surprising that they did not differ in regard to self-determination (i.e. both are freely chosen). These findings extend on Waterman's (1993) early research by establishing differences between hedonia and eudaimonia specifically on a series of variables with documented relevance to intrinsic motivation. He argued that intrinsically motivated activities will be the more "durable and rewarding" pursuits (i.e. eudaimonic activities are better than hedonic activities).

Taken together, Waterman's findings suggest that hedonia and eudaimonia are highly related yet distinct subjective states, which are accompanied by predictable patterns of associated experiences. Eudaimonic activities are characterised by a balance of challenge and skill, the investment of a high degree of effort, the experience of interest and flow, and are associated with opportunities to advance one's personal potentials. By comparison, hedonic activities are associated with feeling relaxed, excited, content, happy, losing track of time, and forgetting one's personal problems. In line with proclamations from eudaimonic philosophy (see Telfer, 1980), Waterman interpreted the asymmetrical relationship observed between hedonia and eudaimonia as evidence that there are three, not four, conceivable categories of activities: (1) those that are experienced as both hedonic and eudaimonic (2) those that are experienced as hedonic but not eudaimonic, and (3) those that are experienced as neither hedonic nor eudaimonic. Eudaimonic activities that were experienced as low in hedonia were argued therefore to be a "theoretical and empirical null". Whilst both hedonia and eudaimonia are positive subjective states, Waterman proposed that eudaimonia is preferable, as it affords opportunities for an individual to develop their potentials and is invariably accompanied by hedonia anyway.

Whilst Waterman's research represents an invaluable theory-driven investigation into the subjective states of hedonia and eudaimonia, some limitations need to be highlighted. Firstly, as Waterman investigated hedonia and eudaimonia at the activity level, conclusions regarding 
the implications of engaging in hedonic and/or eudaimonic activities at a more global level are indiscernible and, as such, should not have been postulated. Despite this, Waterman concluded that eudaimonic pursuits are more "durable and rewarding" than others. It is entirely probable that the context in which the hedonic or eudaimonic activity is engaged in will highly influence whether it is "durable and rewarding". For example, an individual who has a day job which they experience primarily as eudaimonic might find it more rewarding to engage in more hedonic pursuits whilst not at work and these activities may constitute an important source of revitalisation and emotional regulation. Therefore, we believe that proclaiming eudaimonic activities as more rewarding is misleading and untenable from Waterman's findings. Many potential problems with the PEAQ represent further limitations of Waterman's research. Firstly, many individuals may find it difficult, or even inappropriate, to define themselves by their activities; perhaps preferring to define themselves by their values or beliefs. Secondly, the PEAQ may be susceptible to social desirability bias, as participants, to describe who they are, may choose activities which they perceive as socially favoured, despite these not accurately reflecting how they spend their time. This limitation is especially pertinent to Waterman's research as much of the data was collected in a group setting. Lastly, the PEAQ may be susceptible to recall error, as participants are required to retrospectively consider what their typical experience of each activity is, rather than reflecting on a specific instance of engaging in that activity. It has been found that asking people to describe past events may lead to biased recollections that fit with a person's life narrative but may be inconsistent with the frequency, intensity, stability, and value of moment-to-moment experiences (Kashdan et al., 2008). Furthermore, reporting about one's typical experience of an activity disregards all contextual factors that may influence each specific experience of an activity (i.e. it ignores the likelihood that an individual's experience of an activity may differ each time they engage in it, despite it being the same activity).

Furthermore, Waterman et al.'s (2008) interpretation of the asymmetrical relationship as evidence that eudaimonic but not hedonic activities represent a theoretical and empirical null is questionable. When grouping activities as high and low in eudaimonia and hedonia, Waterman et al. used an a priori cut score equivalent to an average item response of 6 on the 7 point scales, which they lauded as a "very stringent criterion for considering an activity to be high" (p. 58). Indeed this constitutes a stringent criterion for an activity to be considered high; however, it simultaneously constitutes an extremely lax criterion for an activity to be considered low (i.e. any score below an average of 6 was considered low). If a stringent criterion was decided upon for considering an activity high, then you would expect an equally stringent criterion for considering an activity low (e.g. an average score of 2 or less). The utilised cut scores lack intuitive appeal and the rationale for such a decision was not explained. Perhaps the category of activities experienced as eudaimonic and not hedonic represents a less likely category of activities; however, it seems extreme and premature to label this category of activities a "theoretical and empirical null".

Counter to Waterman et al.'s (2008) proposition that eudaimonic pursuits are always accompanied by hedonic pleasure is recent research by Vittersø and Søholt (2011). Vitttersø and colleagues have published a number of papers delineating the differences between eudaimonia and hedonia (e.g. Vittersø, 2003; Vittersø, Oelmann, \& Wang, 2009; Vittersø, Søholt, Hetland, Thoresen, \& Røysamb, 2010), and although space does not permit an in-depth review of each, one of Vittersø's most recent investigations will be discussed. Vittersø proposed that the subjective states of hedonia and eudaimonia serve distinct functions, with eudaimonia (which he operationalizes as feelings of interest and engagement) considered important whilst 
pursuing complex goals and when conducting challenging activities, and hedonia (which he operationalizes as feelings of pleasure and satisfaction) considered important for the preservation of stability and for rewarding need fulfilment. Like Waterman et al., Vittersø acknowledges that hedonia and eudaimonia will often be highly correlated (e.g. someone may be pleasantly engaged in an activity that is experienced as interesting and satisfactory); however, he challenges Waterman et al.'s suggestion that eudaimonia is always accompanied by hedonia. Vittersø proposes that personal growth processes are often unrelated to, and sometimes even negatively associated with, pleasant feeling states and overall life satisfaction. Further, Vittersø suggests that pleasure and satisfaction do not motivate effortful behaviour, but are more likely to occur subsequent to effortful behaviour. The crux of Vittersø's argument is that personal growth (which he proposes as a eudaimonic outcome variable) is linked with the emotion of interest (which he considers the hallmark of a eudaimonic activity), whilst life satisfaction (a hedonic outcome variable) is linked with the emotion of pleasure (a hallmark of a hedonic behaviour activity).

To test this, Vittersø and Søholt (2011) had Norwegian Folk High School students complete measures of life satisfaction, personal growth, and both state and trait measures of the emotions of interest (three items: engagement, interest, and enthusiasm) and pleasure (three items: contentment, enjoyment, and happiness). All measures were completed on two separate occasions four months apart, except for the state emotion measure which was only completed at time one in a retrospective manner, whereby participants were required to rate their experience of pleasure and interest during an outdoor experience that occurred three weeks prior. As hypothesised, life satisfaction was found to correlate only modestly with personal growth $(\mathrm{r}<0.30)$. A strong correlation was observed between both personal growth and interest as a trait emotion, and between life satisfaction and pleasure as a trait emotion at both time one (T1) and time two (T2). Regression analyses were conducted with either pleasure or interest as the dependent variable, with life satisfaction being found to be the only significant predictor of pleasure, whilst personal growth was found to be the sole predictor of interest. Path models were also used to estimate the longitudinal relationship between life satisfaction, personal growth, pleasure, and interest, with life satisfaction (T1) being found to predict trait pleasure (T2), whilst trait interest (T1) was found to predict personal growth (T2). As pleasure is a defining aspect of hedonic behaviour and life satisfaction is typically considered a hedonic wellbeing indicator, whilst interest is a defining aspect of eudaimonic behaviour and personal growth a eudaimonic wellbeing indicator, Vittersø and Søholt interpreted the results as evidence of a distinction between hedonia and eudaimonia (both at the activity level and at the wellbeing level).

Vittersø and Søholt's (2011) findings contest Waterman et al.'s (2008) proposition that hedonic pleasures are always present during eudaimonic pursuits, and instead suggest that eudaimonic pursuits are often characterised by the emotional states of interest and engagement. Despite this, Vittersø and Søholt operationalized hedonic and eudaimonic activities differently to Waterman et al., which means direct comparisons between their findings cannot be made. Vittersø and Søholt's study also had the inherent risk of recall error like Waterman et al.'s, as participants were required to retrospectively reflect on how they felt at an earlier period. However, in Vittersø and Søholt's study they were reflecting on a specific instance of activity engagement, which somewhat reduces the risk of recall error. The highly unique sample utilised (i.e. high school students at a school specialising in outdoor education) in Vittersø and Søholt's study also limits the generalizability of their findings. 
Delle Fave et al. (2011a) have also recently investigated hedonia and eudaimonia utilising a unique mixed method approach, containing both qualitative and quantitative methods. They aimed to evaluate whether the philosophical traditions of hedonia and eudaimonia were consistent with what lay people refer to when they speak of wellbeing and happiness. They were also interested in sampling a different population to what had been utilised in the majority of past wellbeing research (i.e. university undergraduate students). A purposefully selected sample from seven different countries (Australia, Croatia, Germany, Italy, Portugal, Spain, and South Africa) included males and females living in urban areas, aged between 30 and 51. Delle Fave et al. were interested in mature people who were passing or had passed through some of the major life stages (e.g. formal education, settled into career, marriage and child bearing), as they believed that such individuals had a greater repertoire of experiences on which to evaluate their happiness and meaningfulness. Participants were asked open-ended questions, requiring them to define what happiness meant to them and what things they found meaningful. They were then required to rate on two 7-point scales the degree of happiness and meaningfulness they associated with 11 different life domains (i.e. Work, Family, Standard of Living, Interpersonal Relationships, Health, Personal Growth, Spirituality/Religion, Society issues, Community issues, Leisure, and Life in general). Participants also completed the Satisfaction with Life Scale (Diener, Emmons, Larsen, \& Griffin, 1985).

Participants were found typically to define happiness in terms of both the contents of happiness (internal dimensions) and the related contexts (situational dimensions). Contextual definitions referred to the life domains participants associated with happiness. Relational aspects were most prominent, with family and social relations accounting for over half the answers, whilst the domain of health followed as the third-ranked domain. These findings suggest that happiness stems predominantly from interpersonal bonds, mainly intimate relationships (with a partner and children in particular) but also from interactions with friends and significant others outside the family. The preponderance of references to relationships suggests that wellbeing has a relational core, which was unsurprising to Delle Fave et al. (2011a), as conceptualisations of wellbeing often emphasise the importance of social connectedness (e.g. Keyes, 2007; Ryff \& Keyes, 1995; Seligman, 2011). Answers referring to content emphasised the psychological structure and characteristics of happiness. Both hedonic and eudaimonic aspects were referred to, with eudaimonic components being more prominent in participants' answers. The most frequently cited content of happiness was harmony and balance (e.g. inner peace, self-acceptance, serenity, and a feeling of balance and evenness), with over $25 \%$ of participants' answers referring to this. Other components that have typically been considered eudaimonic included meaning, engagement, fulfilment, awareness, autonomy, achievement and optimism. When grouped together, eudaimonic references accounted for $38.9 \%$ of participants' definitions of happiness. Hedonic aspects referred to included positive feelings/emotions and satisfaction, which were cited in $23.8 \%$ of the answers. As with contexts, the contents of happiness referred to by participants were consistent with many previous wellbeing conceptualisations (e.g. Ryan \& Deci, 2000; Ryff \& Keyes, 1995). These results, from qualitative research, suggest that the lay-person's perspectives of happiness and wellbeing are relatively consistent with the hedonic and eudaimonic traditions. Further, as participants defined happiness in terms of its contents and associated contexts, future wellbeing conceptualisations may benefit from adopting such a categorical system.

Quantitative findings basically confirmed qualitative results, with the domain of family being ranked highest in terms of its association with both happiness and meaningfulness, whilst the domains of health and interpersonal relations followed. Although ratings of 
meaningfulness and happiness were mostly congruent (i.e. domains associated with meaningfulness were generally also associated with happiness), some incongruences were observed, the most notable of which were within the work domain. Whilst work was associated with a high degree of meaningfulness, it was ranked near the bottom in terms of happiness. This finding contrasts with the position of Waterman et al. (2008), and suggests that meaning can be perceived and pursued in the absence of hedonic happiness. Again however, Delle Fave et al. (2011a) operationalized eudaimonia differently to Waterman et al., which restricts the possibility of drawing direct comparisons. Surprisingly, happiness and meaningfulness ratings explained only $38 \%$ of the variance in life satisfaction, which suggests that $62 \%$ of life satisfaction is explained by other factors. Delle Fave et al. wondered if the difference in global and domain specific judgments may explain this finding, because when making global judgments people rely on multiple sources, and these sources are weighted differently (i.e. global judgments are generally not equal to the sum of domain specific judgments). Delle Fave et al. further pondered whether perhaps ratings of happiness and meaningfulness have participants reflect on more eudaimonic factors (as suggested by the qualitative responses), whilst ratings of life satisfaction have participants reflect on hedonic factors (e.g. desire satisfactions). As highlighted through the review of Waterman and colleagues (Waterman, 1993; Waterman et al., 2008) and Vittersø and Søholt's (2011) research, hedonia and eudaimonia show a positive relationship, but are distinct and independent constructs.

Delle Fave et al.'s (2011a) research suggests that wellbeing is a multifaceted concept, and considering this, they strongly argued against unified wellbeing models which disregard the differences between eudaimonic and hedonic aspects. Ratings of happiness, meaningfulness and life satisfaction varied, in that participants perceived their lives as predominantly meaningful and happy, but as satisfying to a lesser extent. This emphasises the need for jointly evaluating different aspects of wellbeing, and for giving proper relevance to the eudaimonic dimensions. Delle Fave et al. also found that a relatively overlooked dimension of wellbeing, namely harmony/balance, constitutes an important aspect of lay people's conceptions of happiness. This suggests that the commonly held assumptions that more is better may be misleading in terms of happiness and wellbeing, and that perhaps achieving a balance between different needs, commitments and aspirations is more important. Further research is necessary to better disentangle the wellbeing dimension of harmony and balance.

Whilst there were many strengths to Delle Fave et al.'s (2011a) investigation (e.g. mixed method approach, culturally diverse sample, etc.), this research was not without limitations. Firstly, whilst the purposeful selection of the sample in relation to demographics represents a less-investigated population, it does mean that conclusions cannot be generalised outside of this narrow range. Therefore, the plausible hypothesis that the relative importance of hedonia and eudaimonia changes across the life span remains unaddressed. It should also be noted that Delle Fave et al. developed single-item measures of meaning and happiness, which questions the validity and reliability of findings. Future research should therefore attempt to utilise standardised measures of these constructs to more rigorously investigate the constructs of hedonia and eudaimonia. Further, it was unclear from Delle Fave et al.'s procedure section how participants were asked to rate the domains in terms of meaningfulness and happiness. The way participants were asked to rate the domains greatly affects how results should be interpreted. For example, if participants were asked how meaningful a domain was to them, that would be a question about how much they value that domain; however, if they were asked the extent to which they experience a sense of meaning whilst engaged in activities associated with a certain domain, that would be a question about momentary eudaimonia, consistent with 
the way Waterman (1993) conceptualised eudaimonia. Clearly detailing key methodology such as this is critical for assisting with interpretation and replication.

Together, Waterman (1993), Waterman et al.'s (2008), Vittersø and Søholt's (2011), and Delle Fave et al.'s (2011a) research provides a strong argument that hedonia and eudaimonia are distinct, but highly related. Whilst Waterman proposed that eudaimonic pursuits are invariably accompanied by hedonia, Vittersø and Søholt and Delle Fave et al. suggest that eudaimonia is not always accompanied by hedonic enjoyment or pleasure. Vittersø and Søholt's and Delle Fave et al.'s research further suggest that hedonia and eudaimonia are distinguishable at the wellbeing level. With a predominantly conceptual and theoretical focus, this research offers little insight into the broader wellbeing outcomes associated with hedonic and eudaimonic pursuits. Therefore, research investigating eudaimonic and hedonic pathways to wellbeing will now be reviewed.

\subsection{Pathways to wellbeing}

Peterson, Park and Seligman (2005) were the first to utilise an integrated methodology in the investigation of pathways to wellbeing. The crux of this pioneering research was the Orientations to Happiness $(\mathrm{OTH})$ scale. This questionnaire requires individuals to rate whether they typically approach life in search of meaning, pleasure, and/or engagement - these three orientations are not considered mutually exclusive (i.e. an individual can simultaneously be high on all three). This scale reflects Seligman et al.'s (2004) Authentic Happiness theory, with two of the orientations, the pleasant life and the meaningful life, being equated with hedonia and eudaimonia respectively, whilst the engaged life has been equated with flow (Park, Peterson, \& Ruch, 2009). Peterson et al. (2005) found that all three orientations were predictive of life satisfaction, thereby supporting the notion that either hedonic or eudaimonic pathways can lead to wellbeing when pursued in isolation. Despite this, results suggested that an orientation toward meaning and engagement were more robust predictors of life satisfaction relative to pleasure. It was further found that the simultaneous pursuit of all three orientations, termed the full life, was associated with the highest degree of life satisfaction, suggesting that a life rich in both eudaimonic and hedonic pursuits is best. It is notable that this research has since been replicated with a variety of populations (e.g. students, teachers, the elderly) in over 27 nations, with results confirming the strong relationship between the full life and life satisfaction (Chan, 2009; Chen, Tsai, \& Chen, 2010; Park et al., 2009; Ruch, Harzer, Proyer, Park, \& Peterson, 2010; Vella-Brodrick, Park, \& Peterson, 2009).

Despite Peterson et al.'s (2005) research resulting in the development of an integrated model pertaining to pathways to wellbeing (i.e. the full life model), the retrospective crosssectional data collection method, which in this instance required participants to reflect globally on how they typically live, may have been subject to recall error and social desirability bias. This method of questioning asks participants to make cognitive judgements about how they typically live; the assumption being that these judgements will be accurate representations of what participants actually do. The accuracy of such global cognitive judgements has been questioned (Gosling, John, Craik, \& Robins, 1998), and provides limited information regarding how much the individual actually invests in a certain orientation. The OTH questionnaire may be more a measure of attitudes than of behaviour, and it is well established in the literature that attitudes can be a poor predictor of actual behaviour (Ajzen \& Fishbein, 2005). Therefore, it is not discernible from Peterson et al.'s research whether behaving in hedonic and/or eudaimonic ways is associated with life satisfaction, or whether holding hedonic and/or eudaimonic attitudes is. 
Peterson et al.'s (2005) findings that the orientations of engagement and meaning were better predictors of life satisfaction than pleasure runs counter to Vittersø and Søholt's (2011) findings, which suggested that pleasure was a stronger predictor of life satisfaction than engagement and interest. In explanation of this inconsistency, Vittersø and Søholt questioned the validity of the OTH scale, proposing that the orientations were not accurate measures of hedonia and eudaimonia. They cited research showing the pleasure orientation was found to correlate only weakly with other measures of pleasure, and the engagement orientation was found to be uncorrelated with measures of state engagement (Vittersø, Dyrdal, \& Røysamb, 2006). Inherent within the OTH scale appears to be a high risk of social desirability bias, as questions pertaining to the pleasure orientation seem to reflect impulsiveness (e.g. "life is too short to postpone the pleasures it can provide" and "I agree with this statement: life is short eat dessert first") and appear considerably less desirable than all questions pertaining to both the meaning orientation (e.g. "my life serves a higher purpose" and "in choosing what to do, I always take into account whether it will benefit other people") and the engagement orientation (e.g. "I seek out situations that challenge my skills and abilities" and "I am rarely distracted by what is going on around me"). This may have contributed to validity issues, as perhaps the pleasure orientation is more reflective of hedonism (i.e. the pursuit of pleasure as the ultimate good), rather than hedonia (the experience of happiness or pleasure). In any case, further validation is necessary before definitive conclusions can be made based on results from research utilising the OTH scale. A final limitation of Peterson et al.'s research is that life satisfaction was the only outcome measure utilized, thereby limiting possible conclusions regarding the effect of hedonia and eudaimonia on flourishing (i.e. on other dimensions of wellbeing). If multiple facets of wellbeing were measured - both hedonic and eudaimonic - it would be possible to delineate which orientation was associated with benefits in specific wellbeing dimensions.

To rectify the limitation of using only life satisfaction as an outcome measure, Schueller and Seligman (2010) replicated Peterson et al.'s (2005) study with a sample of 13,565 participants and the addition of multiple outcome measures. Added scales included measures of momentary positive and negative affect, measures of more general/average levels of happiness, and the Center for Epidemiologic Studies Depression Scale (CES-D). Schueller and Seligman also included measures of educational and occupational achievements, which they claimed to be "objective" measures of wellbeing. The inclusion of the CES-D in this research represents a step in the right direction as it allows for observations to be made about the relationship between hedonia and eudaimonia and psychological distress. Not only is this reflective of the original goal of the positive psychology movement (i.e. to have a psychology that considers both the negative and positive aspects of the human experience; see Linley et al., 2006), but it is also especially relevant to any interventions that have been developed (e.g. positive psychotherapy), or will be developed based on hedonic and eudaimonic research findings. Positive psychotherapy was born out of Peterson et al.'s findings. Positive psychotherapy assesses clients for deficits in any of the three pathways and clients are encouraged to cultivate these areas (Seligman, Rashid, \& Parks, 2006). This technique has been used as a treatment for depression, despite no empirical association yet being established between the empty life and depression, or the full life and an absence of depression. Although this seems to have occurred in the wrong direction (i.e. the intervention has been developed and utilised before the establishment of empirical associations between depression and the three orientations), the continued inclusion of measures of psychological distress in future investigations of eudaimonia and hedonia is of vital importance. 
Schueller and Seligman's (2010) findings were consistent with previous research utilising the OTH scale, whereby all three pathways were found to individually correlate with life satisfaction. This finding was also observed across other measures, with all three pathways correlating positively with positive wellbeing measures (i.e. subjective happiness scale, positive affect on the PANAS, the Fordyce Emotions Questionnaire, the Authentic Happiness Inventory) and negatively with negative wellbeing measures (i.e. negative affect and CES-D). Also consistent with previous findings was that the orientations of engagement and meaning were found to showed stronger associations with all outcome measures than was the pleasure orientation. Through confirmatory factor analysis, Schueller and Seligman also discovered that the three pathways were reliably distinguishable, but that engagement and meaning had the most significant overlap. This finding lends further credence to Waterman's (1993), Vittersø and Søholt's (2011), and Delle Fave et al.'s (2011a) suggestion that hedonia and eudaimonia are distinct, whilst the stronger association observed between engagement and meaning is consistent with previously proposed theoretical and empirical linkages between flow and eudaimonia (Waterman, 1993).

Surprisingly, the pleasure orientation was less strongly associated with positive affect and happiness than the engagement and meaning orientation. Furthermore, the pleasure orientation was found to be negatively associated with educational and occupational achievement, whilst the engagement and meaning orientations were both positively associated with these outcomes. Schueller and Seligman proposed that Fredrickson's (2004) broaden-andbuild theory of positive emotions might provide an explanation for these findings. The broaden-and-build theory suggests that resources and positive emotions relate to each other in a positive feedback loop, with increases in one leading to subsequent increases in the other. Engagement was argued to result in people seeking out activities that challenge their skills, which helps them develop their talents and interests; whilst meaning was argued to help build social connections and provides purpose, which leads to the development of self-relevant goals. In contrast, the pursuit of pleasure was argued to often not lead to the development of any durable resources, as such pursuits provide only momentary short-lived improvements in mood. Therefore, Schueller and Seligman argued that as the orientations of engagement and meaning are more conducive to the development of sustainable and rewarding resources than a pleasure orientation, it is understandable that those orientations were found to be more strongly associated with the experience of positive emotions and happiness and with educational and occupational achievements.

Adding further support for the full life model was the finding that high scores on all three orientations were associated with the greatest life satisfaction, positive affect, and general happiness, and that this effect was more than an additive combination of each pathway. This finding suggests that although the orientations of engagement and meaning may be more related to higher levels of wellbeing than the orientation of pleasure, a total absence of the pleasure orientation is detrimental to wellbeing. Whilst the combined pursuit of all pathways was strongly associated with wellbeing benefits, it was not found to be predictive of lower levels of negative affect or depression. Schueller and Seligman (2010) argued that this was unsurprising, as the three pathways are considered approaches to happiness and not approaches to reducing negative emotions and psychopathology. This statement came as some surprise, as Seligman has been highly involved in the development and promotion of positive psychotherapy, which suggests that depression can be treated through the pursuit of the three orientations. In contradiction to this, Schueller and Seligman argued that whilst seeking pleasure, engagement, and meaning may be important to increase wellbeing, it may not 
necessarily be helpful for alleviating distress. From this research, Schueller and Seligman concluded that pleasure, engagement, and meaning are all pathways to wellbeing, but they do not contribute equally to wellbeing. As engagement and meaning are associated with the development of resources and the pursuit of long-term goals, it was argued that they are the pathways that are more conducive to long-term wellbeing benefits.

Schueller and Seligman's (2010) investigation makes a significant additional contribution to previous findings by elucidating the three pathways relationship with multiple outcome measures. The finding that the combined pursuit of all three pathways was most beneficial in all outcome measures also lends further credence to the full life model, and again suggests that a life rich in both hedonic and eudaimonic pursuits may be associated with flourishing. Despite this, Schueller and Seligman, like Waterman et al. (2008), argue that eudaimonic pursuits are better than hedonic pursuits at promoting long-term wellbeing. We see a risk in proclaiming one pathway as better, or more rewarding, than another in these early stages of enquiry. From the limited data obtained from cross-sectional research it seems premature to be making such claims, especially considering that such conclusions may be interpreted as cautions against hedonia. Furthermore, the same limitations mentioned above regarding the validity of the OTH scale apply here, and perhaps the finding that the pleasure orientation had weaker associations with positive affect and happiness than the engagement and meaning orientations further questions the validity of the OTH. Furthermore, rather than strengthening this investigation, we believe the addition of the "objective" wellbeing measures of educational and occupational achievement was a weakness of the investigation. Whilst we recognise the inherent value of both education and occupation, it was the way these were operationalized that we disagree with. Firstly, it was admitted that the sample was extremely biased in terms of education, with $89 \%$ having attended college, and 31\% having completed post-college education. With such a homogeneous sample the value of including education as an outcome measure is questionable. Furthermore, only formal education (i.e. high school, college, and post-college) was acknowledged, with other types of education (e.g. self-directed learning) not recognised. In terms of occupational achievement, the researchers ranked occupations based on the "skill level" of the profession, with the highest-ranked jobs being professionals such as chief executives, doctors, lawyers, dentists, and professors. We question the value in this categorical system, as surely job satisfaction or performance would be a more useful outcome measure than an arbitrary ranking system based on "skill level". We would argue that to be good in any job requires a high level of specialised skill in that field. We see a ranking system based on income or societal perspectives of what constitutes a "good" job (which appears to be what was done in this case) as more damaging than helpful to the science of wellbeing.

Steger et al. (2008) rectified many of the limitations associated with the data collection method in studies utilising the OTH scale by having participants reflect on specific instances of hedonic or eudaimonic behaviour. Despite concordantly investigating eudaimonia and hedonia, Steger et al. treated hedonia and eudaimonia as mutually exclusive, in that pursuits were considered to be either one or the other. Steger et al. conducted two daily diary studies, ranging from three weeks (Study 1) to four weeks (Study 2), in which participants were required to report how frequently they engaged in eudaimonic and hedonic behaviours each day. Study 1 had participants report the frequency of engagement in 14 activities (seven hedonic and seven eudaimonic), which were considered by a group of five individuals who had experience in philosophy and psychology to be representative of prototypically eudaimonic and hedonic pursuits. Participants also completed wellbeing questionnaires assessing life satisfaction, positive and negative affect, and meaning in life. The eudaimonic 
behaviours were found to be more frequently engaged in (ratio of 3.5:1) than the hedonic behaviours and were also more strongly associated with wellbeing than hedonic behaviours in all wellbeing dimensions. Furthermore, eudaimonic behaviours were found to lead to more meaning in life and life satisfaction the following day.

Considering the higher frequency of reported eudaimonic behaviours, and out of concern that the seven original hedonic behaviours may have led to a socially desirable response bias towards eudaimonic behaviours, Steger et al. (2008) conducted study 2. They were concerned that perhaps the hedonic behaviours they included, or perhaps how the item responses were worded, may have led to the observed low frequency of reporting, and therefore they reworded three of the items (e.g. "had sex purely to get pleasure" was reworded "had sex with someone I do not love") and added five more hedonic behaviours they expected to be more frequently engaged in (e.g. "spent time listening to music"). Furthermore, Steger et al. included a measure of social desirability in this study. Scores of this scale were found to be uncorrelated with aggregated totals of eudaimonic or hedonic behaviour reporting, which was interpreted as evidence that participants had not responded in a socially desirable manner. Other findings were consistent with study 1 in that eudaimonic behaviours had stronger associations with all wellbeing outcome measures than did hedonic behaviours.

Despite Steger et al.'s (2008) findings suggesting that eudaimonic pathways may be a more effective way to attain personal wellbeing, a number of methodological flaws limit the validity of their findings and conclusions. Steger et al. were determined to investigate the relative contribution of eudaimonic and hedonic activities on wellbeing, and therefore included activities which they considered to be pure representations of each type of activity. We do not consider this a worthy line of investigation for two reasons. Firstly, the issue of context must again be highlighted. The relative contributions of hedonic and/or eudaimonic behaviours should be considered only in the context of an individual's life as a whole. For example, an individual who lives a highly hedonic lifestyle may get wellbeing boosts from engaging in a eudaimonic activity, while a highly eudaimonic individual may need nothing more than a night of hedonic pleasures to boost their wellbeing. The frequency of only seven eudaimonic and seven hedonic activities (ten in the second study) were recorded, which provides limited information regarding what else the participants were doing, or the time period during which the individual may have engaged in a reported behaviour. A participant may have engaged in numerous hedonic or eudaimonic behaviours that were not represented on the list, or may have frequently reported engaging in an activity on the list, yet the time they spent engaged in this activity may have been insignificant. Second, we disagree with the assumption that the behaviours chosen by the researchers were exclusively eudaimonic or hedonic, or that any activity will be universally experienced as hedonic or eudaimonic. The experience of any given activity is highly subjective, and therefore it is the individual who should rate whether an activity was experienced as hedonic or eudaimonic. We would argue that many of the "purely hedonic" activities on the list could be considered highly eudaimonic (e.g. listing to music, going for a long walk, going to a concert, etc.), and vice versa. Further, it is questionable whether exclusively hedonic or eudaimonic behaviours even exist, especially considering the high degree of relatedness that has been observed between hedonia and eudaimonia (Vittersø \& Søholt, 2011; Waterman et al., 2008)

More recently, Huta and Ryan (2010) conducted an investigation into the effect of eudaimonic and hedonic motives on multiple facets of wellbeing. Both cross-sectional and experience sampling studies were conducted, utilising the Hedonic and Eudaimonic Motives for Activities scale, which requires participants to report their motives - either hedonic or 
eudaimonic - for participation in an activity. They utilized an array of wellbeing outcome measures, including life satisfaction, positive and negative affect, carefreeness, meaning in life, vitality and elevating experiences (e.g. inspiration, deep appreciation, and self-transcendence). Principal component analyses confirmed that eudaimonic and hedonic motives were empirically distinct, and moderately related $(r=0.36)$. It was found that hedonic motives were related more strongly to positive affect than eudaimonic motives; however, eudaimonic motives were related to positive affect at 3-month follow-up. Hedonic motives were also found to be negatively related to negative affect, and showed an advantage over eudaimonic motives in this regard. Hedonic motives were found to be more strongly related to carefreeness, whilst eudaimonic motives were more strongly associated with meaning and elevating experiences. Eudaimonic and hedonic motives were equally associated with vitality and life satisfaction. Notwithstanding these more intricate findings, overall results indicated that people whose lives were high in both eudaimonic and hedonic motives had the highest degree of wellbeing as reflected in all dimensions (i.e. they were found to be flourishing), than predominantly eudaimonically motivated individuals, predominantly hedonically motivated individuals, and those whose lives were low in both motives. Huta and Ryan concluded that these findings lend further credence to the full life model of wellbeing proposed by Peterson et al (2005).

Huta and Ryan's (2010) study rectified several of the previously mentioned limitations of past research. The degree of eudaimonia and hedonia was rated by the participants and these were investigated in parallel terms, meaning any given motive for an activity could potentially be rated simultaneously high in eudaimonia and hedonia, or high in one or the other, or low in both. Furthermore, the inclusion of an array of wellbeing outcome measures meant that the relative association between eudaimonia, hedonia and the different facets of flourishing could be investigated. Finally, the experience-sampling method used by Huta and Ryan meant the risk of recall error and social desirability bias should have been reduced. Results suggested that hedonic motives are more closely associated with immediate emotional regulation, as evidenced by the strong positive association observed between hedonic motives and positive affect and carefreeness and the negative correlation observed between hedonic motives and negative affect. There also appeared to be a temporal sequence between eudaimonic motives and positive affect, whereby eudaimonia resulted in positive affect boosts down the track (perhaps when goals are achieved), which is consistent with Steger et al.'s (2008) and Vittersø and Søholt's (2011) findings.

Despite these methodological improvements, Huta and Ryan (2010) distinguished eudaimonic and hedonic motives for participating in an activity from the individual's actual experience of the activity. It could be argued that the experience of an activity would have much more influence on one's overall wellbeing than an individual's intentions for engaging in an activity (Wirtz, Kruger, Napa Scollon, \& Diener, 2003). It could be further argued that a person's intentions for engaging in an activity may be unrelated or even negatively correlated with wellbeing. For example, one may engage in an activity with eudaimonic or hedonic motives only to be disappointed if the intended experience does not eventuate. Furthermore, although the experience-sampling method utilised does potentially minimise recall error and social desirability bias, it does not capture comprehensive behavioural information. It is possible that participants may be continuously paged whilst engaged in insignificant activities, and not whilst engaged in significant activities. Again, like in Steger at al.'s (2008) and Peterson et al.'s (2005) studies, the specifics about how much an individual invests in either hedonic or eudaimonic pathways is not discernible from the data obtained. 
In combination, past research using integrated methodologies suggests that hedonia and eudaimonia are distinct subjective states that are associated with distinct wellbeing outcomes. Hedonia at the activity level is characterised by experiences of pleasure and enjoyment, and has been strongly associated with experiences of satisfaction, positive affect and happiness at the wellbeing level. Eudaimonia at the activity level is characterised by feelings of authenticity, engagement, and interest and has been associated with experiences of meaning and purpose in life and personal growth at the wellbeing level. Associations have also been observed between eudaimonic motives and life satisfaction and positive affect, and a temporal sequence has been observed, whereby eudaimonic pursuits appear to lead to positive affective experiences later. These observations suggest that both hedonic and eudaimonic pathways are associated with wellbeing benefits when pursued in isolation. Despite this, some research (e.g. Peterson et al., 2005; Steger et al., 2008; Schueller \& Seligman, 2010) suggests that eudaimonic pathways are more robust predictors of wellbeing than hedonic pathways. However, the validity of such assertions is questionable due to methodological limitations. When considered together, rather than compared, a life that is rich in hedonic and eudaimonic pursuits - the full life - appears to most strongly predict flourishing; however, the limitations of past research means that definitive conclusions cannot yet be reached. Such limitations include data collection methods that are susceptible to both social desirability bias and recall error; erroneous assumptions that activities are objectively eudaimonic or hedonic or that pursuits must be exclusively eudaimonic or hedonic; homogenous and unrepresentative samples; and the limited inclusion of only a few wellbeing outcome dimensions.

\section{Directions for future research}

The issues listed at the end of the previous paragraph remain to be addressed by future research efforts to further progress this important area of enquiry. While research into hedonia and eudaimonia remains in its infancy, research must focus on confirming or contesting what has thus far been postulated, whilst also refining methodologies to reach more practically relevant conclusions. Currently, data suggest that if someone typically approaches life with, or has a high frequency of, randomized eudaimonic or hedonic motives, they will flourish; however, the practical utility of these assertions is questionable. Instructing someone to live a life high in both eudaimonic and hedonic motives is a somewhat ambiguous and equivocal instruction. Further, investigation into the practical details of the full life, such as whether a particular period of time spent engaged in eudaimonic or hedonic pursuits is associated with flourishing; the degree to which eudaimonic or hedonic components of activities are related to wellbeing; the relationship between hedonia and eudaimonia; and whether the relative need for hedonic or eudaimonic pursuits to optimize wellbeing differs across the life-span, remains essential. Addressing such pragmatic questions will not only be useful in further establishing the validity of the model, but will also be informative for beginning the important transition from explaining and describing to applying and prescribing.

Considering that most past research has been cross-sectional and focused on subjective global self-perceptions, a research focus that includes a more complete behavioural analysis is now necessary. This type of data would be useful in further establishing the validity of the full life model, as behavioural data could be cross referenced with previously used measures (e.g. OTH scale) to test construct validity. As experience-sampling has already been used to obtain a limited randomized sample of behaviours, future investigations should aim to obtain more comprehensive behavioural reports of how individuals actually spend their time and how the way in which individuals spend their time relates to wellbeing. If an individual is reporting the 
activities they have actually taken part in (rather than making an unspecified global assessment about how they typically live) and their experience of those activities (as either hedonic or eudaimonic), the risk of recall error would be greatly reduced. Combining time-use research methods, such as the day reconstruction method (Kahneman, Krueger, Schkade, Schwarz, \& Stone, 2004), with hedonic and eudaimonic rating scales, such as the HEMA scale (Huta \& Ryan, 2010), would make the collection of such data possible. Whilst this research methodology may potentially be onerous for participants, online data collection methods or mobile phone reporting could mitigate the burden.

This type of data is what is necessary to address the issue of context, which has been alluded to throughout this article. It is the authors' belief that we need to move away from asking questions about whether hedonic or eudaimonic pursuits are better at promoting wellbeing. This only encourages unhelpful dichotomous thinking, and ignores the fact that hedonic and eudaimonic pursuits both play important roles in the promotion of wellbeing. Rather than pitting hedonia and eudaimonia against each other, research should attempt to identify when a specific type of pursuit is indicated for the promotion of wellbeing. Like many aspects of life, it is likely that too much hedonia or eudaimonia will be detrimental to wellbeing, and that optimal experiences of wellbeing will be associated with striking a balance between the two. The use of the label "full life" connotes that more is better, which is unlikely to be the case. Perhaps the "balanced life" may be a more appropriate label (as was recently theoretically argued (see Sirgy \& Wu, 2009)); however, further research is necessary to establish whether this is the case. If research finds that investing a certain amount of time in eudaimonic and hedonic pursuits is associated with flourishing, then a practical guideline could be established to help identify and rectify imbalances. Time-use research methods are what will ultimately shed more light on this matter.

A further benefit of focussing on specific instances of hedonic and eudaimonic behaviour rather than global self-assessments is that behaviours are malleable and therefore amenable to change, making them a good target for intervention. Behavioural activation treatments, whereby an activity schedule is prescribed to a patient with depression, have been found to be highly effective treatments (Dimidjian et al., 2006). As treatments aimed at increasing the general level of activity have been successful for relieving depression, the identification of eudaimonic and hedonic patterns associated with flourishing could make for targeted and effective interventions to enhance wellbeing. Activating eudaimonic or hedonic behaviours may also assist in ameliorating symptoms of distress and/or psychopathology. Although Schueller and Seligman's (2010) research suggests that the full life is not associated with decreased depression, we believe that it is premature to conclude that interventions aimed at promoting hedonic and eudaimonic activation and balance will not be effective in relieving psychological distress. Therefore, it is recommended that future investigations continue to include measures of psychopathology so that the relationship between distress and hedonia and eudaimonia can be further elucidated.

The continued use of rating scales is also recommended to investigate how the intensity of the hedonic or eudaimonic components of an activity relates to wellbeing return (i.e. wellbeing benefits). It may be that engaging in mildly hedonic activity does not have the same wellbeing benefits as engaging in moderately or highly hedonic activity. By combining the intensity of a person's hedonic or eudaimonic experience with the time they spent engaged in the respective pursuits, questions such as whether there is an interaction between the two or whether one mediates the other could be addressed. Perhaps engaging in one hour of mildly hedonic activity is only slightly beneficial to wellbeing but as the degree of hedonia increases, the 
amount of time engaged in that activity may decrease whilst maintaining the same mild benefit to wellbeing.

The relationship between hedonic and eudaimonic pursuits themselves, and how this relationship influences wellbeing, also requires further investigation. Whilst some research suggests that eudaimonic pursuits are always accompanied by hedonic pursuits (Waterman et al., 2008), other research suggests that eudaimonia can be experienced in the absence of hedonia (Delle Fave et al., 2011a; Vittersø \& Søholt, 2011). Given such disagreement, further research is necessary to clarify that issue. The causal nature of this relationship also requires investigation. For instance, it has often been assumed that eudaimonic behaviours lead to hedonic enjoyment, yet the opposite has also been observed: hedonia has been shown to lead to eudaimonic outcomes (King et al., 2006), which suggests there may be a reciprocal relationship between hedonia and eudaimonia. Furthermore, although it is intuitively appealing to assume that those activities that are experienced as both hedonic and eudaimonic would be associated with the greatest wellbeing benefits, this requires empirical support. If this assumption is empirically confirmed, then ways of identifying the activities an individual may experience as both hedonic and eudaimonic will be a useful line of investigation.

Lastly, past homogeneous samples means it is now necessary to incorporate an array of age groups and demographic factors to investigate whether the findings are consistent across a more diverse population. Furthermore, there is merit in the investigation of pathways to wellbeing across the lifespan, since the relative importance of hedonic and eudaimonic pursuits may vary at different stages of life. It has been found that peoples' conceptions of wellbeing change with age, and that although good relationships and the pursuit of enjoyable activities are consistently endorsed as important components of wellbeing across the lifespan, younger adults have a greater focus on self-knowledge, competence, and self-acceptance, while older adults focus more on positively coping with change (Carstensen, 1998; Erikson \& Erikson, 1997; Ryff, 1989). Considering these differences in the desires and needs associated with wellbeing, it is intuitive to think that younger and older adults would have differing pathways to flourishing. Comparing the activity profile of stratified age ranges could help elucidate the differing needs of adults in relation to eudaimonic and hedonic activities.

\section{Conclusion}

The hedonic and eudaimonic perspectives both contribute to a comprehensive understanding of wellbeing, and should therefore be integrated. Findings from the limited research that has simultaneously investigated hedonia and eudaimonia suggests that they are distinct but highly related subjective experiences, and that both hedonic and eudaimonic pursuits can lead to wellbeing benefits; however it is also suggested that eudaimonic pursuits are associated with greater wellbeing benefits than are hedonic pursuits, and that a life rich in both hedonic and eudaimonic pursuits is associated with the greatest degree of wellbeing benefits. Despite this, significant research limitations require rectification in order to establish the validity and accuracy of such conclusions. Future research endeavours should abandon the past tendency to compare and contrast hedonia and eudaimonia so as to establish which is better. Instead the inherent value of both hedonia and eudaimonia should be recognised and attempts should be made to investigate more comprehensively how these operate in the overall context of an individual's life. Future methodologies should move away from cross-sectional designs assessing global cognitive self-perceptions and instead should attempt to capture more accurately and comprehensively how participants actually live their lives (hedonically and/or eudaimonically) and how this relates to their wellbeing. Findings from such research could not 
only add construct validity to previous research, but would also make it possible to transition from purely descriptive conclusions to more applied and practically relevant conclusions, which could be informative in the development of interventions potentially useful for both the enhancement of wellbeing and the reduction of distress.

\section{Authors}

Luke Wayne Henderson

Deakin University

1.henderson@deakin.edu.au

Tess Knight

Deakin University

\section{Publishing Timeline}

Received 18 January 2012

Accepted 23 May 2012

Published 29 August 2012

\section{References}

Ajzen, I., \& Fishbein, M. (2005). The influence of attitudes on behavior. In A. Albarracín, B. T. Johnson \& M. P. Zanna (Eds.), The handbook of attitudes (pp. 173-221). New Jersey: Lawrence Erlbaum Associates. Aristotle. (1985). Nicomachean ethics (T. Irwin, Trans.). Indianapolis: Hackett.

Baumeister, R. F., \& Vohs, K. D. (2002). The pursuit of meaningfulness in life. In S. J. Lopez, \& C. R. Snyder (Eds.), Handbook of positive psychology (pp. 608-618). New York: Oxford University Press.

Biswas-Diener, R., Kashdan, T. B., \& King, L. A. (2009). Two traditions of happiness research, not two distinct types of happiness. The Journal of Positive Psychology, 4(3), 208-211. http://dx.doi.org/10.1080/17439760902844400

Carstensen, L. L. (1998). A life-span approach to social motivation. In J. Heckhausen, \& C. S. Dweck (Eds.), Motivation and self-regulation across the life span (pp. 341-364). New York: Cambridge University Press. http://dx.doi.org/10.1017/CBO9780511527869.015

Chan, D. W. (2009). Orientations to happiness and subjective well-being among Chinese prospective and in-service teachers in Hong Kong. Educational Psychology, 29(2), 139-151. http://dx.doi.org/10.1080/01443410802570907

Chen, L., Tsai, Y. M., \& Chen, M. Y. (2010). Psychometric analysis of the orientations to happiness questionnaire in Taiwanese undergraduate students. Social Indicators Research, 98(2), 239-249. http://dx.doi.org/10.1007/s11205-009-9473-2

Csikszentmihalyi, M. (1988). The flow experience and its significance for human psychology. Cambridge: Cambridge University Press.

Csikszentmihalyi, M. (1991). Flow: The psychology of optimal experience. New York: Harper Perennial.

Csikszentmihalyi, M. (1997). Creativity: Flow and the psychology of discovery and invention. New York: Harper Perennial.

Deci, E. L., \& Ryan, R. M. (1985). Intrinsic motivation and self-determination in human behavior. New York: Springer.

Deci, E. L., \& Ryan, R. M. (2008). Hedonia, eudaimonia, and well-being: an introduction. Journal of Happiness Studies, 9(1), 1-11. http://dx.doi.org/10.1007/s10902-006-9018-1

Delle Fave, A., \& Bassi, M. (2009). The contribution of diversity to happiness research. The Journal of Positive Psychology, 4(3), 205-207. http://dx.doi.org/10.1080/17439760902844319

Delle Fave, A., Brdar, I., Freire, T., Vella-Brodrick, D., \& Wissing, M. (2011a). The eudaimonic and hedonic components of happiness: Qualitative and quantitative findings. Social Indicators Research, 100(2), 185-207. http://dx.doi.org/10.1007/s11205-010-9632-5 
Delle Fave, A., Massimini, F., \& Bassi, M. (2011b). Hedonism and eudaimonism in positive psychology In A. Delle Fave (Ed.), Psychological Selection and Optimal Experience Across Cultures: Social Empowerment through Personal Growth (Vol. 2, pp. 3-18). New York: Springer.

Diener, E. (2009). Subjective well-being. In E. Diener (Ed.), The science of well-being: The collected works of Ed Diener (Vol. 37, pp. 11-58). New York: Springer.

Diener, E., Emmons, R. A., Larsen, R. J., \& Griffin, S. (1985). The satisfaction with life scale. Journal of Personality Assessment, 49(1), 71-75. http://dx.doi.org/10.1207/s15327752jpa4901 13

Dimidjian, S., Hollon, S. D., Dobson, K. S., Schmaling, K. B., Kohlenberg, R. J., Addis, M. E., Gallop, R., McGlinchey, J. B., Markley, D. K., Gollan, J. K., Atkins, D. C., Dunner, D. L., \& Jacobson, N. S. (2006). Randomized trial of behavioral activation, cognitive therapy, and antidepressant medication in the acute treatment of adults with major depression. Journal of Consulting and Clinical Psychology, 74(4), 658-670. http://dx.doi.org/10.1037/0022-006x.74.4.658

Erikson, E. H., \& Erikson, J. M. (1997). The life cycle completed. New York: W. W. Norton.

Forgeard, M. J. C., Jayawickreme, E., Kern, M. L., \& Seligman, M. E. (2011). Doing the right thing: Measuring wellbeing for public policy. International Journal of Wellbeing, 1(1).

Fredrickson, B. L. (2000). Cultivating positive emotions to optimize health and well-being. Prevention $\mathcal{E}$ Treatment, 3(1), No Pagination Specified. http://dx.doi.org/10.1037/1522-3736.3.1.31a

Fredrickson, B. L. (2001). The role of positive emotions in positive psychology: The broaden-and-build theory of positive emotions. American Psychologist, 56(3), 218-226. http://dx.doi.org/10.1037/0003066x.56.3.218

Fredrickson, B. L. (2004). The broaden-and-build theory of positive emotions. Philosophical Transactions of the Royal Society B: Biological Sciences, 359(1449), 1367-1378. http://dx.doi.org/10.1098/rstb.2004.1512

Gosling, S. D., John, O. P., Craik, K. H., \& Robins, R. W. (1998). Do people know how they behave? Selfreported act frequencies compared with on-line codings by observers. Journal of Personality and Social Psychology, 74(5), 1337-1349. http://dx.doi.org/10.1037/0022-3514.74.5.1337

Grinde, B. (2012). The Biology of Happiness. New York: Springer. http://dx.doi.org/10.1007/978-94-0074393-9

Hsu, C. L., \& Lu, H. P. (2004). Why do people play on-line games? An extended TAM with social influences and flow experience. Information \& Management, 41(7), 853-868.

http://dx.doi.org/10.1016/j.im.2003.08.014

Huppert, F. A., \& So, T. (2009). What percentage of people in Europe are flourishing and what characterises them. Paper presented at the Paper prepared for the OECD/ISQOLS meeting, Measuring subjective well-being: An opportunity for NSOs?, Florence.

Huta, V. (2012). Linking peoples' pursuit of eudaimonia and hedonia with characteristics of their parents: Parenting styles, verbally endorsed values, and role modeling. Journal of Happiness Studies, 13(1), 47-61. http://dx.doi.org/10.1007/s10902-011-9249-7

Huta, V., \& Ryan, R. M. (2010). Pursuing pleasure or virtue: The differential and overlapping well-being benefits of hedonic and eudaimonic motives. Journal of Happiness Studies, 11(6), 735-762. http://dx.doi.org/10.1007/s10902-009-9171-4

Kahneman, D. (1999). Objective happiness. In D. Kahneman, E. Diener, \& N. Schwarz (Eds.), Well-being: The foundations of hedonic psychology (pp. 1). New York: Sage.

Kahneman, D., Diener, E., \& Schwarz, N. (1999). Well-being: The foundations of hedonic psychology. New York: Sage.

Kahneman, D., Krueger, A. B., Schkade, D. A., Schwarz, N., \& Stone, A. A. (2004). A survey method for characterizing daily life experience: the day reconstruction method. Science, 306(5702), 1776-1780. http://dx.doi.org/10.1126/science.1103572

Kashdan, T. B., Biswas-Diener, R., \& King, L. A. (2008). Reconsidering happiness: the costs of distinguishing between hedonics and eudaimonia. The Journal of Positive Psychology, 3(4), 219-233. http://dx.doi.org/ 10.1080/17439760802303044

Keyes, C. L. (2006). The subjective well-being of America's youth: Toward a comprehensive assessment. Adolescent \& Family Health, 4(1), 3-11. 
Keyes, C. L. (2007). Promoting and protecting mental health as flourishing: A complementary strategy for improving national mental health. American Psychologist, 62(2), 95-108. http://dx.doi.org/10.1037/0003-066x.62.2.95

Keyes, C. L., \& Annas, J. (2009). Feeling good and functioning well: distinctive concepts in ancient philosophy and contemporary science. The Journal of Positive Psychology, 4(3), 197-201. http://dx.doi.org/10.1080/17439760902844228

Keyes, C. L., Wissing, M., Potgieter, J. P., Temane, M., Kruger, A., \& van Rooy, S. (2008). Evaluation of the mental health continuum-short form (MHC-SF) in setswana-speaking South Africans. Clinical Psychology \& Psychotherapy, 15(3), 181-192. http://dx.doi.org/10.1002/cpp.572

King, L. A., Hicks, J. A., Krull, J. L., \& Del Gaiso, A. K. (2006). Positive affect and the experience of meaning in life. Journal of Personality and Social Psychology, 90(1), 179-196. http://dx.doi.org/10.1037/0022-3514.90.1.179

Linley, A. P., Joseph, S., Harrington, S., \& Wood, A. M. (2006). Positive psychology: Past, present, and (possible) future. The Journal of Positive Psychology, 1(1), 3-16. http://dx.doi.org/10.1080/17439760500372796

McDowell, J. (1980). The Role of Eudaimonia in Aristotle's Ethics'. In A. O. Rorty (Ed.), Essays on Aristotle's ethics (pp. 359-376). Berkeley: University of California Press.

Norton, D. L. (1976). Personal Destinies. Princeton: Princeton University Press.

Park, N., Peterson, C., \& Ruch, W. (2009). Orientations to happiness and life satisfaction in twenty-seven nations. The Journal of Positive Psychology, 4(4), 273-279. http://dx.doi.org/10.1080/17439760902933690

Peterson, C., Park, N., \& Seligman, M. E. P. (2005). Orientations to happiness and life satisfaction: the full life versus the empty life. Journal of Happiness Studies, 6(1), 25-41. http://dx.doi.org/10.1007/s10902$\underline{004-1278-\mathrm{Z}}$

Ruch, W., Harzer, C., Proyer, R. T., Park, N., \& Peterson, C. (2010). Ways to Happiness in GermanSpeaking Countries. European Journal of Psychological Assessment, 26(3), 227-234. http://dx.doi.org/10.1027/1015-5759/a000030

Ryan, R. M. (1992). Agency and organization: Intrinsic motivation, autonomy, and the self in psychological development. Nebraska Symposium on Motivation, 40, 1-56.

Ryan, R. M., \& Deci, E. L. (2000). Self-determination theory and the facilitation of intrinsic motivation, social development, and well-being. American Psychologist, 55(1), 68-78. http://dx.doi.org/10.1037/0003-066X.55.1.68

Ryan, R. M., \& Deci, E. L. (2001). On happiness and human potentials: A review of research on hedonic and eudaimonic well-being. Annual Review of Psychology, 52, 141-166. http://dx.doi.org/10.1146/annurev.psych.52.1.141

Ryan, R. M., \& Huta, V. (2009). Wellness as healthy functioning or wellness as happiness: The importance of eudaimonic thinking (response to the Kashdan et al. and Waterman discussion). The Journal of Positive Psychology, 4(3), 202-204. http://dx.doi.org/10.1080/17439760902844285

Ryff, C. D. (1989). Happiness is everything, or is it? Explorations on the meaning of psychological wellbeing. Journal of Personality and Social Psychology, 57(6), 1069-1081. http://dx.doi.org/10.1037/0022$\underline{3514.57 .6 .1069}$

Ryff, C. D., \& Keyes, C. L. (1995). The structure of psychological well-being revisited. Journal of Personality and Social Psychology, 69(4), 719-727. http://dx.doi.org/10.1037/0022-3514.69.4.719

Schueller, S. M., \& Seligman, M. E. (2010). Pursuit of pleasure, engagement, and meaning: Relationships to subjective and objective measures of well-being. The Journal of Positive Psychology, 5(4), 253-263. http://dx.doi.org/10.1080/17439761003794130

Seligman, M. E. P. (2011). Flourish: A visionary new understanding of happiness and well-being. New York: Free Press.

Seligman, M. E. P., \& Csikszentmihalyi, M. (2000). Positive psychology. An introduction. American Psychologist, 55(1), 5-14. http://dx.doi.org/10.1037/0003-066X.55.1.5

Seligman, M. E. P., Parks, A. C., \& Steen, T. (2004). A balanced psychology and a full life. Philosophical Transactions of the Royal Society B: Biological Sciences, 359(1449), 1379-1381. http://dx.doi.org/10.1098/rstb.2004.1513 
Seligman, M. E. P., Rashid, T., \& Parks, A. C. (2006). Positive psychotherapy. American Psychologist, 61(8), 774-788. http://dx.doi.org/10.1037/0003-066x.61.8.774

Sirgy, M. J., \& Wu, J. (2009). The pleasant life, the engaged life, and the meaningful life: What about the balanced Life? Journal of Happiness Studies, 10(2), 183-196. http://dx.doi.org/10.1007/s10902-007-9074-1

Steger, M. F., Kashdan, T. B., \& Oishi, S. (2008). Being good by doing good: Daily eudaimonic activity and well-being. Journal of Research in Personality, 42(1), 22-42.

http://dx.doi.org/10.1016/j.jrp.2007.03.004

Telfer, E. (1980). Happiness. New York: St. Martin's Press.

Tiberius, V., \& Hall, A. (2010). Normative theory and psychological research: Hedonism, eudaimonism, and why it matters. The Journal of Positive Psychology, 5(3), 212-225.

http://dx.doi.org/10.1080/17439761003790971

Vella-Brodrick, D., Park, N., \& Peterson, C. (2009). Three ways to be happy: Pleasure, engagement, and meaning - findings from Australian and US samples. Social Indicators Research, 90(2), 165-179. http://dx.doi.org/10.1007/s11205-008-9251-6

Vittersø, J. (2003). Flow versus life Satisfaction: A projective use of cartoons to illustrate the difference between the evaluation approach and the intrinsic motivation approach to subjective quality of life. Journal of Happiness Studies, 4(2), 141-167. http://dx.doi.org/10.1023/a:1024413112234

Vittersø, J., Dyrdal, G. M., \& Røysamb, E. (2006). Why can't we measure engagement with life satisfaction scales? Some theoretical and empirical arguments about their distinctiveness. Paper presented at the The 3rd European Conference on Positive Psychology, Braga, Portugal.

Vittersø, J., Oelmann, H., \& Wang, A. (2009). Life Satisfaction is not a Balanced Estimator of the Good Life: Evidence from Reaction Time Measures and Self-Reported Emotions. Journal of Happiness Studies, 10(1), 1-17. http://dx.doi.org/10.1007/s10902-007-9058-1

Vittersø, J., \& Søholt, Y. (2011). Life satisfaction goes with pleasure and personal growth goes with interest: Further arguments for separating hedonic and eudaimonic well-being. The Journal of Positive Psychology, 6(4), 326-335. http://dx.doi.org/10.1080/17439760.2011.584548

Vittersø, J., Søholt, Y., Hetland, A., Thoresen, I., \& Røysamb, E. (2010). Was Hercules happy? Some answers from a functional model of human well-being. Social Indicators Research, 95(1), 1-18. http://dx.doi.org/10.1007/s11205-009-9447-4

Waterman, A. S. (1990). Personal expressiveness: Philosophical and psychological foundations. Journal of Mind and Behavior, 11(1), 47-73.

Waterman, A. S. (1993). Two conceptions of happiness: Contrasts of personal expressiveness (eudaimonia) and hedonic enjoyment. Journal of Personality and Social Psychology, 64(4), 678-691. http://dx.doi.org/10.1037/0022-3514.64.4.678

Waterman, A. S. (2005). When effort is enjoyed: Two studies of intrinsic motivation for personally salient activities. Motivation and Emotion, 29(3), 165-188. http://dx.doi.org/10.1007/s11031-005-9440-4

Waterman, A. S. (2008). Reconsidering happiness: a eudaimonist's perspective. The Journal of Positive Psychology, 3(4), 234-252. http://dx.doi.org/10.1080/17439760802303002

Waterman, A. S., Schwartz, S., \& Conti, R. (2008). The implications of two conceptions of happiness (hedonic enjoyment and eudaimonia) for the understanding of intrinsic motivation. Journal of Happiness Studies, 9(1), 41-79. http://dx.doi.org/10.1007/s10902-006-9020-7

Waterman, A. S., Schwartz, S. J., Goldbacher, E., Green, H., Miller, C., \& Philip, S. (2003). Predicting the subjective experience of intrinsic motivation: the roles of self-determination, the balance of challenges and skills, and self-realization values. Personality and Social Psychology Bulletin, 29(11), 1447-1458. http://dx.doi.org/10.1177/0146167203256907

Wirtz, D., Kruger, J., Napa Scollon, C., \& Diener, E. (2003). What to do on spring break? The role of predicted, on-line, and remembered experience in future choice. Psychological Science, 14(5), 520-524. http://dx.doi.org/10.1111/1467-9280.03455 